\title{
Association Between Meat and Meat- Alternative Consumption and Iron Stores in Early Childhood
}

Kelly Anne Cox, MPH, Patricia C. Parkin, MD, FRCPC, Laura N. Anderson, PhD, Yang Chen, MSc, Catherine S. Birken, MD, MSc, FRCPC, Jonathon L. Maguire, MD, MSc, FRCPC, Colin Macarthur, $\mathrm{MBChB}, \mathrm{PhD}$, Cornelia M. Borkhoff, $\mathrm{PhD}$, on behalf of the TARGet Kids! Collaboration

\author{
Version Published version/ final PDF \\ Citation Kelly Anne Cox, Patricia C. Parkin, Laura N. Anderson, Yang Chen, \\ (published version) Catherine S. Birken, Jonathon L. Maguire, Colin Macarthur, Cornelia M. \\ Borkhoff, Association Between Meat and Meat-Alternative \\ Consumption and Iron Stores in Early Childhood, In Academic \\ Pediatrics, Volume 16, Issue 8, 2016, Pages 783-791, ISSN 1876-2859, \\ https://doi.org/10.1016/j.acap.2016.01.003. \\ Copyright/License \\ (c) (i) $\odot$ This work is licensed under the Creative Commons \\ BY NC ND Attribution-NonCommercial-NoDerivatives 4.0 \\ International License. To view a copy of this license, visit \\ http://creativecommons.org/licenses/by-nc-nd/4.0/.
}

How to cite TSpace items

Always cite the published version, so the author(s) will receive recognition through services that track citation counts, e.g. Scopus. If you need to cite the page number of the author manuscript from TSpace because you cannot access the published version, then cite the TSpace version in addition to the published version using the permanent URI (handle) found on the record page.

This article was made openly accessible by $U$ of $T$ Faculty. Please tell us how this access benefits you. Your story matters. 


\section{Accepted Manuscript}

The association between meat and meat alternatives consumption and iron stores in early childhood

Kelly Anne Cox, MPH, Patricia C. Parkin, MD, FRCPC, Laura N. Anderson, PhD, Yang Chen, MSc, Catherine S. Birken, MD, MSc, FRCPC, Jonathon L. Maguire, MD,

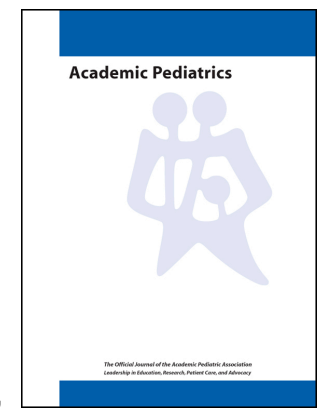
MSc, FRCPC, Colin Macarthur, MBChB, PhD, Cornelia M. Borkhoff, PhD, on behalf of the TARGet Kids! Collaboration

PII: S1876-2859(16)00019-X

DOI: 10.1016/j.acap.2016.01.003

Reference: $\quad$ ACAP 801

To appear in: Academic Pediatrics

Received Date: 17 March 2015

Revised Date: 4 January 2016

Accepted Date: 11 January 2016

Please cite this article as: Cox KA, Parkin PC, Anderson LN, Chen Y, Birken CS, Maguire JL, Macarthur $\mathrm{C}$, Borkhoff CM, on behalf of the TARGet Kids! Collaboration, The association between meat and meat alternatives consumption and iron stores in early childhood, Academic Pediatrics (2016), doi: 10.1016/ j.acap.2016.01.003.

This is a PDF file of an unedited manuscript that has been accepted for publication. As a service to our customers we are providing this early version of the manuscript. The manuscript will undergo copyediting, typesetting, and review of the resulting proof before it is published in its final form. Please note that during the production process errors may be discovered which could affect the content, and all legal disclaimers that apply to the journal pertain. 


\title{
The association between meat and meat alternatives consumption and iron stores in early childhood
}

\author{
Kelly Anne Cox, $\mathrm{MPH}^{1}$, Patricia C. Parkin, MD, FRCPC ${ }^{1,2,3,4}$, Laura N. Anderson, $\mathrm{PhD}^{1}$, \\ Yang Chen, $\mathrm{MSc}^{5}$, Catherine S. Birken, MD, MSc, FRCPC ${ }^{1,2,3,4}$, \\ Jonathon L. Maguire, MD, MSc, FRCPC ${ }^{1,2,3,5,6}$, \\ Colin Macarthur, MBChB, PhD ${ }^{1,2,3,4}$, Cornelia M. Borkhoff, $\mathrm{PhD}^{1,2,4}$ \\ on behalf of the TARGet Kids! Collaboration*
}

*TARGet Kids! Collaboration - Scientific Committee: Kawsari Abdullah, Laura N. Anderson, Imaan Bayoumi, Catherine S. Birken, Cornelia M. Borkhoff, Sarah Carsley, Yang Chen, Mikael Katz-Lavigne, Kanthi Kavikondala, Christine Koroshegyi, Christine Kowal, Grace Jieun Lee, Jonathon L. Maguire, Dalah Mason, Jessica Omand, Patricia C. Parkin, Navindra Persaud, Meta van den Heuvel, Peter Wong, Weeda Zabih; Site Investigators: Jillian Baker, Tony Barozzino, Joey Bonifacio, Douglas Campbell, Sohail Cheema, Brian Chisamore, Karoon Danayan, Paul Das, Mary Beth Derocher, Anh Do, Michael Dorey, Sloane Freeman, Keewai Fung, Charlie Guiang, Curtis Handford, Hailey Hatch, Sheila Jacobson, Tara Kiran, Holly Knowles, Bruce Kwok, Sheila Lakhoo, Margarita Lam-Antoniades, Eddy Lau, Fok-Han Leung, Jennifer Loo, Sarah Mahmoud, Rosemary Moodie, Julia Morinis, Sharon Naymark, Patricia Neelands, James Owen, Michael Peer, Marty Perlmutar, Navindra Persaud, Andrew Pinto, Michelle Porepa, Nasreen Ramji, Noor Ramji, Alana Rosenthal, Janet Saunderson, Rahul Saxena, Michael Sgro, Susan Shepherd, Barbara Smiltnieks, Carolyn Taylor, Thea Weisdors, Sheila Wijayasinghe, Peter Wong, Ethel Ying, Elizabeth Young.

\section{Affiliations:}

'Division of Paediatric Medicine and the Paediatric Outcomes Research Team (PORT), Hospital for Sick Children, Toronto, ON, Canada

${ }^{2}$ Institute of Health Policy, Management and Evaluation, University of Toronto, Toronto, ON, Canada

${ }^{3}$ Department of Pediatrics, Faculty of Medicine, University of Toronto, Toronto, ON, Canada.

${ }_{5}^{4}$ Child Health Evaluative Sciences, Sick Kids Research Institute, Toronto, ON, Canada

${ }^{5}$ The Applied Health Research Centre of the Li Ka Shing Knowledge Institute, St. Michael's Hospital, Toronto, ON, Canada

${ }^{6}$ Department of Paediatrics, St. Michael's Hospital, Toronto, ON, Canada

Corresponding Author: Cornelia M. Borkhoff, $\mathrm{PhD}$, Division of Paediatric Medicine, Department of Paediatrics, The Hospital for Sick Children, Room 109801, $10^{\text {th }}$ Floor - Peter Gilgan Centre for Research and Learning, 686 Bay Street, Toronto, ON M5G 0A4 Canada; Tel: 416-813-7654 X309135; Fax: 416-813-5663; E-mail: cory.borkhoff@ sickkids.ca

Keywords: meat consumption; iron deficiency; early childhood

Short Title: Meat consumption and iron status in early childhood

Word count (excluding abstract, box, tables, figures and references): 3500 
Funding: Funding to support TARGet Kids! was provided by multiple sources including the Canadian Institutes for Health Research (CIHR), namely the Institute of Human Development, Child and Youth Health and the Institute of Nutrition, Metabolism and Diabetes, as well as, the St. Michael's Hospital Foundation. The Paediatric Outcomes Research Team is supported by a grant from The Hospital for Sick Children Foundation. Funding agencies had no role in the design, collection, analyses or interpretation of the results of this study or in the preparation, review, or approval of the manuscript.

Financial Disclosure: The authors have no financial relationships relevant to this article to disclose.

Conflicts of Interest: None.

\section{Contributor's Statement}

Kelly Anne Cox, Cornelia M. Borkhoff: Ms. Cox and Dr. Borkhoff conceptualized and designed the study, carried out the analysis, drafted the initial manuscript, and approved the final version of the manuscript.

Patricia C. Parkin: Dr. Parkin conceptualized and designed the study, critically reviewed the manuscript, and approved the final version of the manuscript.

Laura N. Anderson, Yang Chen: Dr. Anderson and Mr. Chen provided feedback on the analyses, critically reviewed the manuscript, and approved the final version of the manuscript.

Catherine S. Birken, Jonathon L. Maguire, and Colin Macarthur: Drs. Birken, Maguire and Macarthur designed the data collection instruments, supervised the data collection, critically reviewed the manuscript, and approved the final version of the manuscript.

All authors agree to be accountable for all aspects of the work. 


\section{ABSTRACT}

Objective: To prevent iron deficiency, 2014 Canadian recommendations for healthy term infants from six to 24 months recommend iron-rich complementary foods such as meat/meat alternatives two or more times a day. The purpose of our study was to evaluate the association between meat/meat alternatives consumption and iron status in young children and the association between red meat consumption and iron status among children meeting recommendations. Methods: Healthy children, ages 12-36 months, were recruited. A cross-sectional study was conducted. Meat/meat alternatives consumption was measured using the NutriSTEP® questionnaire. Adjusted multivariable regression analyses were used to evaluate an association between meat consumption and serum ferritin, and iron deficiency (serum ferritin $<14 \mu \mathrm{g} / \mathrm{L}$ ). Results: 1043 children were included. $73 \%$ of children met the recommended daily intake of meat $/$ meat alternatives and $66 \%$ ate red meat in the past three days. Eating meat/meat alternatives was not associated with serum ferritin $(0.13 \mu \mathrm{g} / \mathrm{L}, 95 \% \mathrm{CI}:-0.05$ to $0.31, P=0.16)$, but was associated with a decreased odds of iron deficiency (odds ratio $=0.97,95 \%$ CI:0.94 to $0.99, P=0.03$ ). Associations between red meat consumption and iron status were not statistically significant. Statistically significant covariates associated with increased odds of iron deficiency included longer breastfeeding duration, daily cow's milk intake $>2$ cups, and a higher zBMI. Discussion: Daily cow's milk intake > 2 cups, longer breastfeeding duration, and a higher zBMI are modifiable risk factors associated with iron deficiency. Eating meat according to recommendations may be a promising additional target for the prevention of iron deficiency in early childhood.

\section{Word count: 248}




\section{What's New}

Higher meat or meat alternatives consumption among 12- to 36-month-old children modestly but significantly reduced the risk for iron deficiency. Our findings highlight that when combined with other healthy feeding practices, eating meat according to current recommendations may prevent iron deficiency in early childhood. 


\section{INTRODUCTION}

Early childhood is a critical period in human development. ${ }^{1}$ Iron deficiency anemia is known to be associated with delays in early childhood cognitive development which may be irreversible, and has been associated with long-term educational, cognitive and emotional impairments. ${ }^{2}$ Iron deficiency peaks in prevalence during the toddler years (1-3 years) largely due to nutritional factors. ${ }^{2}$ In Canada, studies suggest a prevalence of iron deficiency amongst young children of $12 \%$ or higher, and a prevalence of $1.5 \%$ or higher for iron deficiency anemia. ${ }^{3}$ This is similar to the United States, where the prevalence of iron deficiency among $1-2$ year olds is $14 \%{ }^{4,5}$ Diet and feeding practices established in early childhood have the potential to prevent iron deficiency and optimize human development.

In 2003, the World Health Organization (WHO) and the Pan American Health Organization (PAHO) published unified, scientifically-based guiding principles for complementary feeding of the breastfed child. ${ }^{6}$ The guidelines recommend introducing complementary foods at 6 months of age while continuing to breastfeed, and that "meat, poultry, fish or eggs should be eaten daily, or as often as possible" to ensure the nutrient needs of the child. $^{6}$

There has been increasing interest in examining the role of meat as a first complementary food with respect to iron status in infancy. ${ }^{7}$ However, the results of observational and randomized trials of the relationship between meat and iron status in early childhood have been inconsistent. $^{8-18}$

In Canada, screening for iron deficiency is not recommended. ${ }^{19}$ However, social policies, such as maternity and parental leave benefits for up to one year, ${ }^{20}$ support breastfeeding and other healthy feeding practices. Breastfeeding initiation is high (90\%), more than half of women 
report exclusive breastfeeding at three months and any breastfeeding at six months, and complementary foods are introduced on average at 4.8 months. ${ }^{21}$ In 2014 , Health Canada, Canadian Paediatric Society, Dieticians of Canada, and Breastfeeding Committee for Canada published a joint statement for healthy term infants from six to 24 months of age. ${ }^{19}$ Introduction of complementary feeding is recommended at about six months of age, parents and caregivers are advised to "first introduce iron-rich meat and meat alternatives, and iron-fortified cereals", and to offer iron-rich foods two or more times a day. ${ }^{19}$ Meat is emphasized as an important source of heme-iron that is highly bioavailable compared with non-heme iron sources found in meat alternatives (e.g., legumes) and iron-fortified cereals. ${ }^{19}$

In the United States, breastfeeding initiation is at $79 \%$, and $49 \%$ of infants are breastfeeding at six months of age. ${ }^{22}$ The American Academy of Pediatrics similarly recommends iron-rich first foods, although no specific number of servings are suggested; instead, it focuses on the total amount of iron required in the diet $(7 \mathrm{mg} /$ day for a 1-3 year old $){ }^{2}$ The relationship between the consumption of meat and meat alternatives and the iron status of young children has not been previously examined in Canadian children. The purpose of this study was to evaluate the association between meat and meat alternatives consumption and iron status in young children. For our secondary objective we sought to determine the association between red meat consumption and iron status among children meeting current Canadian recommendations for meat consumption. 


\section{METHODS}

\section{Participants}

This was a cross-sectional study of healthy urban children, ages 12 to 36 months who attended scheduled health supervision visits at a TARGetKids! participating pediatric or family medicine primary care practice in Toronto, Canada between March 2008 and March 2015. TARGetKids! is a primary care practice-based research network set in Toronto, Canada (www.targetkids.ca) ${ }^{23}$ Study participants were recruited by research personnel embedded in 9 participating clinics. Sociodemographic, lifestyle and nutritional information were collected during a scheduled visit through a standardized parent-completed survey instrument based on the Canadian Community

Health Survey. ${ }^{24}$ Laboratory tests were also collected at these visits; for children with more than one visit, the first visit with serum ferritin testing was included in the analysis.

Exclusion criteria were: chronic conditions except asthma, severe developmental delay, impaired growth, and families unable to communicate in English. We restricted the ages to $12-$ 36 months because iron deficiency is most prevalent during this period. ${ }^{3}$ Children with elevated C-reactive Protein $(\geq 10 \mathrm{mg} / \mathrm{L})$, a marker of inflammation, were excluded because it can distort serum ferritin levels. ${ }^{25}$ Children receiving iron supplementation or a daily multivitamin with iron were excluded. We also excluded children with missing data on the exposure variables or outcome variable.

Consent was obtained from parents and ethical approval was granted from the Research Ethics Boards at The Hospital for Sick Children and St. Michael's Hospital.

\section{Exposure Variables}


Parents completed the NutriSTEP® questionnaire (Nutrition Screening Tool for Every

Preschooler $)^{26}$ to assess our main predictor variable, meat or meat alternatives consumption. The NutriSTEP® is a parent-administered 17-item nutrition screening questionnaire. Validity has been examined with a registered dietitian assessment (based on clinical assessment, 3 days of dietary recall and anthropometric measurements), with area under the receiver operating characteristic curve $>73 \%$; reliability has an intra-class correlation coefficient of 0.89 . Meat or meat alternatives consumption was determined through parental response to the question: "My child usually eats meat, fish, poultry, or alternatives: (alternatives can be eggs, peanut butter, tofu, nuts, and cooked beans, chickpeas and lentils) a) More than 2 times a day; b) 2 times a day; c) Once a day; d) A few times a week; e) Not at all." The frequency of meat consumption was treated as a continuous variable, and recoded to reflect weekly meat consumption: $0=$ Not at all; 3=A few times a week; 7=Once a day; 14=2 times a day; and, 21=More than 2 times a day. Those who answered more than 2 times a day and 2 times a day were coded as eating meat or meat alternatives according to current Canadian recommendations (yes/no).

Our second predictor variable was red meat consumption. This was determined through parental response to the following question: "Please specify your child's diet in the past 3 days. Please check all that apply." Those who checked red meat (beef, veal, pork, lamb, etc.) were coded as eating red meat (yes/no).

\section{Outcome Variables}

Our main outcome variable was iron status. Serum ferritin has been described as the best indicator of iron stores in the absence of inflammation. ${ }^{27}$ The American Academy of Pediatrics notes that hemoglobin concentration as a measure of iron status lacks specificity and sensitivity, 
and recommends measurement of serum ferritin and C-reactive protein. ${ }^{2}$ We measured serum ferritin using a Roche Modular platform (Roche Diagnostics, http://www.roche.com/diagnostics) at the Mount Sinai Services Laboratory. We used serum ferritin both as a continuous variable and as a binary variable (serum ferritin $<14 \mu \mathrm{g} / \mathrm{L}$ ) to classify children as having iron deficiency, which was the cutoff used in the US National Health and Nutrition Examination Survey $\left(\right.$ NHANES). ${ }^{28}$

\section{Other Variables}

Included in the analysis were covariates we a priori predicted might influence serum ferritin or both meat consumption and serum ferritin. These included parent-reported: age; sex; birth weight; maternal ethnicity; total breastfeeding duration (determined from the response to the question, "For how long has your child been breastfed?" - children who had never breastfed were classified as having a breastfeeding duration of 0 months and those currently breastfeeding were classified as having a breastfeeding duration equal to the child's current age); daily cow's milk intake (defined as daily number of 250-mL cups per day); bottle use (determined from the response to the question: “Does your child currently use a bottle?"); grain product intake (determined through parental response to the NutriSTEP® question: "My child usually eats grain products: Examples are bread, bagel, bun, cereal, pasta, rice, roti and tortillas a) More than 5 times a day; b) 4 to 5 times a day; c) 2 to 3 times a day; d) Less than 2 times a day."); and, fruit and vegetable intake (determined from the response to the question: "Please specify your child's diet in the past 3 days. Please check all that apply." - those who checked fruits and/or vegetables were coded as fruit and/or vegetable intake (yes/no)). Daily cow's milk intake was dichotomized into $\leq 2$ cups and $>2$ cups per day, consistent with dietary recommendations. Also included were: 
zBMI and neighbourhood household income. Trained study staff measured participants' standing height in metres (or length for children under 2 years old) and weight in kilograms with standardized instruments. BMI was calculated as $\mathrm{kg} / \mathrm{m}^{2} .{ }^{29}$ World Health Organization growth chart standards were used to determine BMI $z$ scores. ${ }^{29}$ Median after-tax neighbourhood household income was calculated based on postal code using the Statistics Canada Postal Code Conversion File and data from the 2006 Canadian Census. ${ }^{30}$

\section{Statistical Analysis}

Descriptive statistics were performed for the main outcome, exposures and covariates. To assess the association between meat and meat alternatives consumption and serum ferritin level, we used a multivariable linear regression model adjusted for prespecified covariates. All covariates were specified a priori and included in the final model. From a previous study, serum ferritin was known to not be normally distributed. ${ }^{31}$ Residual plots of serum ferritin against meat consumption were generated to verify the presence of a nonlinear relationship between the main predictor and the primary outcome. To accommodate the skewed distribution, serum ferritin was $\log$ transformed and then later back-transformed to aid in the interpretation of our results. Multivariable logistic regression was used to evaluate the association between meat and meat alternatives consumption and iron deficiency, adjusting for all covariates described earlier. We used similar models to meet our secondary objective: determine the association between red meat consumption and serum ferritin level, as well as iron deficiency, among children eating meat or meat alternatives according to current Canadian guidelines. 
Several biologically plausible interactions were considered, including interactions between meat consumption and each of age, sex, total breastfeeding duration, BMI z score, daily cow's milk intake, current bottle use, grain product intake and fruit and vegetable intake. A likelihood ratio test between the main effects model and the model with all plausible interaction terms yielded a joint $P$ value of $P>0.30$ for all models, making all hypothesized interactions unlikely. The Akaike Information Criterion (AIC) also suggested that the models without the interactions were the best fit. Multicollinearity was examined using correlation matrices and a variance inflation factor of greater than 4 . We assessed our models for outliers, homoscedasticity and normality using regression diagnostics, and residual and normal quantile plots. Missing data were handled by multiple imputation using the fully conditional specification method. The maximum rate of missing data for any variable was $9 \%$. Statistical significance was defined as $P<0.05$; all statistical tests were two-sided. Statistical analysis was conducted using SAS statistical software version 9.3 (SAS Institute Inc., Cary, NC, USA). 


\section{RESULTS}

A total of 4199 children ages 12-36 months were recruited to participate; of these, 1746 children had blood assessed for serum ferritin values (Figure 1). Previous TARGet Kids! work has found those who opt to have blood sampled are similar in demographics to those who do not. ${ }^{31}$ Of the 1746 children with serum ferritin values, 1187 had data on meat consumption. Of these, 55 children either had C-reactive Protein values $\geq 10 \mathrm{mg} / \mathrm{L}$ or missing and were excluded. A further 89 children receiving iron supplementation or a daily multivitamin with iron or missing data on these variables were excluded.

Descriptive characteristics of the final study population $(n=1043)$ are shown in Table 1. A total of $759(72.8 \%)$ children ate meat or meat alternatives according to current Canadian recommendations, and $689(66.1 \%)$ children ate red meat in the past three days. Of the 759 children meeting current Canadian recommendations for meat consumption, 535 (70.5\%) children ate red meat in the past three days. Median serum ferritin was $26 \mu \mathrm{g} / \mathrm{L}$ (range 2-159 $\mu \mathrm{g} / \mathrm{L}$ ), and the prevalence of iron deficiency (serum ferritin $<14 \mu \mathrm{g} / \mathrm{L}$ ) was $17.0 \%$.

In the primary analysis, using multivariable linear regression we found no association between meat or meat alternatives consumption and serum ferritin $(0.13 \mu \mathrm{g} / \mathrm{L}, 95 \% \mathrm{CI}:-0.05$ to $0.31, P=0.16$ ) (Table 2 ). The results of this fully adjusted analysis were not substantially different from the unadjusted analysis $(0.14 \mu \mathrm{g} / \mathrm{L}, 95 \% \mathrm{CI}$ : -0.04 to $0.31, P=0.13)$. Statistically significant covariates associated with decreased serum ferritin included longer breastfeeding duration (-0.42 $\mu \mathrm{g} / \mathrm{L}$ for every additional month of breastfeeding, $95 \%$ CI: -0.60 to -0.24$)$, higher zBMI (-1.60 $\mu \mathrm{g} / \mathrm{L}$ for every additional unit in BMI z-score, 95\% CI: -2.45 to -0.72$)$, and daily cow's milk intake $>2$ cups $(-3.55 \mu \mathrm{g} / \mathrm{L}, 95 \% \mathrm{CI}$ : -5.32 to -1.64$)$. Female sex, current bottle use, 
and fruit and vegetable intake in the past 3 days were significantly associated with increased serum ferritin levels.

In univariate analyses, we found a decreased odds of iron deficiency with higher meat consumption $(\mathrm{OR}=0.97,95 \% \mathrm{CI}: 0.94$ to $0.99, P=0.04)$. The proportion of children with iron deficiency among children eating meat or meat alternatives more than two times per day, two times per day, once per day, a few times per week, and not at all, was $14 \%, 17 \%, 18 \%, 26 \%$, and $14 \%$, respectively. Of the 7 children not eating any meat, while only 1 child was found to be iron deficient $(1 / 7=14 \%)$ based on the serum ferritin cut-off of $<14 \mu \mathrm{g} / \mathrm{L}, 2$ children had a serum ferritin of $15 \mu \mathrm{g} / \mathrm{L}$. After adjusting for all covariates, the association between meat or meat alternatives consumption and iron deficiency remained statistically significant $(\mathrm{OR}=0.97,95 \%$ CI: 0.94 to $0.99, P=0.03$ ) (Table 3). Statistically significant covariates associated with increased odds of iron deficiency included longer breastfeeding duration (OR=1.06, 95\% CI: 1.03 to 1.09), higher zBMI (OR=1.35, 95\% CI: 1.15 to 1.59$)$, and daily cow's milk intake $>2$ cups $(\mathrm{OR}=1.82$, 95\% CI: 1.26 to 2.63$)$.

For our secondary analysis, within the group of children who ate meat or meat alternatives according to recommendations, we found no association between red meat consumption and serum ferritin (Table 4) or with iron deficiency (Table 5). Statistically significant covariates associated with decreased serum ferritin included longer breastfeeding duration, higher zBMI, and daily cow's milk intake $>2$ cups. Fruit and vegetable intake in the past 3 days was significantly associated with increased serum ferritin. Longer breastfeeding duration, higher zBMI, and lower birth weight were associated with an increased odds of iron deficiency. 


\section{DISCUSSION}

In this study of young, healthy Canadian children ages 12 to 36 months attending scheduled health supervision visits, $73 \%$ ate meat or meat alternatives according to Canadian recommendations (at least two times per day). ${ }^{19}$ While increased meat consumption was not associated with average serum ferritin levels, we found a very modest, but significant, $3 \%$ reduction in iron deficiency, suggesting that lower meat intake is a risk factor for iron deficiency. We found no association between red meat consumption and iron status amongst those children who ate meat or meat alternatives according to recommendations.

The odds of iron deficiency appear to decrease by $3 \%$ (OR=0.97, 95\% CI: 0.94 to 0.99 , $P=0.03$ ) with a one-unit increase in meat or meat alternatives consumption (i.e., 1 time per week). The precision of the effect estimate and hence narrow confidence interval is both due to a large sample size and treating our ordinal predictor variable as a continuous variable. The frequency of meat consumption was treated as a continuous variable assigning values to the 5 different response options to reflect weekly meat consumption and the 'true' spacing between categories $(0=$ Not at all, $3=\mathrm{A}$ few times a week, $7=$ Once a day, $14=2$ times a day, and, $21=$ More than 2 times a day). $P$ was $<0.05$ demonstrating a statistically significant linear trend, while the test for deviations from linearity was not significant which supports treating meat consumption as a continous variable.

Observational studies from other developed countries, have reported a positive association between meat consumption and iron status in infancy and early childhood. ${ }^{8-11}$ Differences in the measurement of meat consumption and differences in outcome variables (serum ferritin and iron deficiency) may explain why findings have been inconsistent. For example, in an analysis of data from the UK National Diet and Nutrition Survey of over 700 children aged 1.5 to 4.5 years, 
children in the lowest quintile of meat consumption had the highest rates of iron deficiency (ferritin $<10 \mu \mathrm{g} / \mathrm{L}$ ). ${ }^{8}$ In a study of 263 healthy, 1.5 - to 6-year-old children in Israel, iron deficiency was assessed according to the frequency of meat consumption in three categories: seldom, once per week, two or more times per week (4 times more likely to have iron deficiency for seldom compared with two or more times per week). ${ }^{11}$ In our study, we treated the frequency of meat consumption in five categories: not at all, a few times per week, once per day, two times per day, more than two times per day, as a continuous variable and considered both serum ferritin and iron deficiency as outcome variables. Another important distinction is that only one of the previous studies controlled for a number of potential confounding variables identified in the present study ${ }^{11}-$ most adjusted only for age and/or sex.

Several randomized trials have evaluated meat consumption and iron status in infants and young children. ${ }^{12-18}$ Two trials, from Denmark and Germany, compared a low meat and high meat intervention in the first year of life. ${ }^{12,13}$ One of these studies identified a difference in hemoglobin but not serum ferritin; ${ }^{12}$ the other found no differences in hemoglobin or serum ferritin. ${ }^{13}$ Four studies, from Canada, the US (two studies), and a global cohort (Democratic Republic of Congo, Zambia, Guatemala, and Pakistan), compared meat and iron-fortified cereal. ${ }^{14-17}$ Three of these studies identified no differences in iron status; ${ }^{14-16}$ one large study $(\mathrm{n}=1,062)$ found that iron status was significantly more favorable for the cereal group. ${ }^{17}$ Finally, one trial from New Zealand compared a high-meat diet, iron-fortified milk and unmodified cow's milk in young children in the second year of life and found no differences in iron status between the three groups. ${ }^{18}$

In previous cross-sectional studies, our group identified feeding practices associated with an increased risk of iron deficiency in early childhood. We found an almost 2-fold association 
between iron depletion and daytime bottle-feeding compared with cup feeding; ${ }^{32}$ an association between higher cow's milk intake and lower serum ferritin, such that every $250 \mathrm{~mL}$ of cow's milk consumed was associated with a $3.6 \%$ decrease in serum ferritin; ${ }^{33}$ and, a $5 \%$ increase in odds of iron deficiency with each additional month of breastfeeding and 1.7-fold increase in the odds of iron deficiency among children who are breastfed beyond 12 months of age. ${ }^{31}$ Finally, a national cohort of children with severe iron deficiency anemia (hemoglobin $<80 \mathrm{~g} / \mathrm{L}$ ), compared with a regional cohort of iron sufficient children without anemia, consumed a larger volume of cow's milk daily, and were more likely to use a bottle during the day, and also in bed. ${ }^{34}$ These findings support the AAP recommendations for increasing iron stores in young children: limiting cow's milk intake and iron supplementation for infants breastfeeding beyond 12 months of age.

An additional observation in our study was the strong negative relationship between zBMI and iron status. This suggests that overweight/obesity may be another modifiable risk factor associated with iron deficiency to be considered by primary care physicians in preventing iron deficiency in young children. We plan to further evaluate this association in a future crosssectional analyses.

Strengths of our study include a large sample of healthy children recruited from community-based primary healthcare settings. The large sample size provided precise effect estimates and hence narrow confidence intervals. We included children attending scheduled visits for preventive care, and excluded children with laboratory evidence of elevated CRP. To measure meat consumption, we used a question from the NutriSTEP ${ }^{\circ}$ questionnaire shown to be a valid and reliable assessment of the nutritional status of preschool-aged children. ${ }^{26} \mathrm{We}$ included other sources of iron, such as grain product intake, and the intake of fruits and vegetables which may be high in vitamin $\mathrm{C}$, known to enhance non-heme iron absorption when 
consumed at the same meal, ${ }^{35}$ as covariates in our statistical models. Limitations of our study include the cross-sectional design from which causality cannot be determined. In addition, parent reported measurement of meat consumption may be subject to measurement error and too crude to detect associations. While they may be more time-intensive, food diaries may be a better measurement tool to assess both meat consumption and intake of fruits and vegetables. Furthermore, iron-fortified infant cereal consumption was not included as a covariate due to the high rate of missing values. However, infant cereals are intended for the 6 to 12 month age group; our age group was 12 to 36 months and after 12 months, infants should be eating table food. Further, it is possible that our measure of the frequency of meat consumption was less discriminatory (i.e., 3 of 5 response options available to parents were for $\geq 1$ time per day) compared to other studies and therefore unable to detect an association with serum ferritin levels. However, less than $10 \%$ of our cohort consumed meat less than once per day. Finally, data from this population may not be generalizable to children from other urban areas or non-urban children; however, the prevalence of iron deficiency was similar to other Canadian studies of this age group. ${ }^{3}$

\section{Conclusion}

This study and other evidence suggests that excess cow's milk intake and prolonged breastfeeding are significant risk factors for iron deficiency and therefore, should be the focus of education and counseling. Higher meat or meat alternatives consumption modestly but significantly reduced the risk for iron deficiency in our cohort of healthy, young, urban Canadian children, 12 to 36 months of age. When combined with other healthy feeding practices, eating 
meat according to current recommendations may be a promising additional target for the prevention of iron deficiency in early childhood. 
Figure 1. Participant flow chart 


\section{REFERENCES}

1. Hertzman C, Williams R. Making early childhood count. CMAJ. 2009;180(1):68-71.

2. Baker RD, Greer FR. Committee on Nutrition American Academy of Pediatrics.

Diagnosis and prevention of iron deficiency and iron-deficiency anemia in infants and young children (0-3 years of age). Pediatrics. 2010;126(5):1040-1050.

3. Hartfield D. Iron deficiency is a public health problem in Canadian infants and children. Paediatr Child Heal. 2010;15(6):347-350.

4. Cogswell ME, Looker AC, Pfeiffer CM, et al. Assessment of iron deficiency in US preschool children and nonpregnant females of childbearing age : National Health and Nutrition Examination Survey 2003 - 20061 - 4. 2009;(C):1-9.

5. Smelser N, Wilson WJ, Mitchell F. America Becoming: Racial Trends and Their Consequences, Volume II. Washington, DC.: National Academies Press; 2001.

6. PAHO/WHO. Guiding Principles for Complementary Feeding of the Breastfed Child. Washington, DC: PAHO/WHO; 2003.

7. Hambidge KM, Sheng X, Mazariegos M, Jiang T, et al. Evaluation of meat as a first complementary food for breastfed infants: impact on iron intake. Nutr Rev. 2011;69(Suppl 1):S57-S63.

8. Thane CW, Walmsley CM, Bates CJ, Prentice A, Cole TJ. Risk factors for poor iron status in British toddlers: further analysis of data from the National Diet and Nutrition Survey of children aged 1.5-4.5 years. Public Heal Nutr. 2000;3(4):433-440.

9. Taylor A, Redworth EW, Morgan JB. Influence of diet on iron, copper, and zinc status in children under 24 months of age. Biol Trace Elem Res. 2004;97:197-214. 
10. Öhlund I, Lind T, Hörnell A, Hernell O. Predictors of iron status in well-nourished 4-y-old children. Am J Clin Nutr. 2008;87(4):839-845.

11. Moshe G, Amitai Y, Korchia G, et al. Anemia and iron deficiency in children: association with red meat and poultry consumption. J Pediatr Gastroenterol Nutr.. 2013;57:722-727.

12. Engelmann MD, Sandström B, Michaelsen KF. Meat intake and iron status in late infancy: an intervention study. J Pediatr Gastroenterol Nutr. 1998;26(1):26-33.

13. Dube K, Schwartz J, Mueller MJ, Kalhoff H, Kersting M. Complementary food with low $(8 \%)$ or high $(12 \%)$ meat content as source of dietary iron: a double-blinded randomized controlled trial. Eur J Nutr. 2010;49(1):11-18.

14. Yeung GS, Zlotkin SH. Efficacy of meat and iron-fortified commercial cereal to prevent iron depletion in cow milk-fed infants 6 to 12 months of age: a randomized controlled trial. Can J Public Health. 2000;91(4):263-267.

15. Krebs NF, Westcott JE, Butler N, Robinson C, Bell M, Hambidge KM. Meat as a first complementary food for breastfed infants: feasibility and impact on zinc intake and status. J Pediatr Gastroenterol Nutr. 2006;42(2):207-214.

16. Krebs NF, Sherlock LG, Westcott J, et al. Effects of different complementary feeding regimens on iron status and enteric microbiota in breastfed infants. J Pediatr. 2013;163(2):416-423.

17. Krebs NF, Mazariegos M, Chomba E, et al. Randomized controlled trial of meat compared with multimicronutrient-fortified cereal in infants and toddlers with high stunting rates in diverse settings. Am J Clin Nutr. 2012;96:840-847. 
18. Szymlek-Gay EA, Ferguson EL, Heath AM, Gray AR, Gibson RS. Food-based strategies improve iron status in toddlers : a randomized controlled trial. Am J Clin Nutr. 2009;90(6):1541-1551.

19. Health Canada, Canadian Paediatric Society, Dieticians of Canada, Breastfeeding Committee for Canada. Nutrition for Healthy Term Infants: Recommendations from Six to 24 Months, 2014.

http://www.hc-sc.gc.ca/fn-an/nutrition/infant-nourisson/recom/index-eng.php Accessed November 15, 2014.

20. Government of Canada. Maternity and Parental Leave. 2014;2014(November 17). http://www.fcac-acfc.gc.ca/Eng/forConsumers/lifeEvents/havingChildren/Pages/MaternitCongeacu.aspx.

21. Public Health Agency of Canada. What Mothers Say: The Canadian Maternity Experiences Survey. Ottawa; 2009.

22. Center for Disease Control. Breastfeeding Report Card: United States, 2014. http://www.cdc.gov/breastfeeding/pdf/2014breastfeedingreportcard.pdf. Accessed December 13, 2014.

23. Carsley S, Borkhoff CM, Maguire JL, et al. Cohort Profile: The Applied Research Group for Kids (TARGet Kids!) . Int J Epidemiol. 2014. doi:10.1093/ije/dyu123.

24. Statistics Canada. Canadian Community Health Survey. 2011;2014(June 26).

25. Soh P, Ferguson EL, McKenzie JE, Homs MY V, Gibson RS. Iron deficiency and risk factors for lower iron stores in 6-24-month-old New Zealanders. Eur J Clin Nutr. 2004;58(1):71-79. 
26. Randall Simpson JA, Keller HH, Rysdale LA, Beyers JE. Nutrition Screening Tool for Every Preschooler (NutriSTEP(TM)): validation and test-retest reliability of a parentadministered questionnaire assessing nutrition risk of preschoolers. Eur J Clin Nutr. 2008;62(6):770-780.

27. Zimmermann MB. Methods to assess iron and iodine status. Br J Nutr. 2008;99 (Suppl 3):S2-9.

28. Cogswell ME, Looker AC, Pfeiffer CM, et al. Assessment of iron deficiency in US preschool children and nonpregnant females of childbearing age: National Health and Nutrition Examination Survey 2003-2006. Am J Clin Nutr. 2009;89(5):1334-1342.

29. World Health Organization. WHO Child Growth Standards: Methods and Development. Length/height-for-Age, Weight-for-Age, Weight-for-Length, Weight-for-Height and Body Mass Index-for-Age.; 2006.

http://www.who.int/childgrowth/publications/technical_report_pub/en/.

30. Wilkins R. Automated Geographic Coding Based on the Statistics Canada Postal Code Conversion Files, Including Postal Codes through March 2009. Ottawa: Statistics Canada; 2010.

31. Maguire JL, Salehi L, Birken CS, et al. Association between total duration of breastfeeding and iron deficiency. Pediatrics. 2013;131(5):e1530-e1537.

32. Sutcliffe TL, Khambalia A, Westergard S, Jacobson S, Peer M, Parkin PC. Iron depletion is associated with daytime bottle-feeding in the second and third years of life. Arch Pediatr Adolesc Med. 2006;160(11):1114-1120.

33. Maguire JL, Lebovic G, Kandasamy S, et al. The relationship between cow's milk and stores of vitamin D and iron in early childhood. Pediatrics. 2013;131(1):1-8. 
34. Parkin PC, DeGroot J, Maguire JL, Birken CS, Zlotkin S. Severe iron deficiency anemia and feeding practices in young children. Public Heal Nutr. 2015 Jun 1:1-7. [Epub ahead of print: doi:10.1017/S1368980015001639].

35. Center for Disease Control. Recommendations to Prevent and Control Iron Deficiency in the United States. MMWR 1998;47(No. RR-3):5.

http://www.cdc.gov/nutrition/everyone/basics/vitamins/iron.html. Accessed December 19, 2014. 
Acknowledgements: We would like to thank all of the participating families for their time and involvement in TARGet Kids! and are grateful to all practitioners who are currently involved in the TARGet Kids! research network. Steering Committee: Tony Barozzino, Brian Chisamore, Mark Feldman, Moshe Ipp. Research Team: Kathleen Abreo, Dharma Dalwadi, Tarandeep Malhi, Antoinetta Pugliese, Megan Smith, Laurie Thompson. Applied Health Research Centre: Christopher Allen, Hannah Chung, Gerald Lebovic, Magda Melo. Mount Sinai Services Laboratory: Azar Azad. 
Table 1. Demographic characteristics of study participants $(n=1043)$

\begin{tabular}{|c|c|c|}
\hline $\begin{array}{r}\text { Child Characteristics } \\
\end{array}$ & Frequency $(\mathbf{N}, \%)$ & Median (range) \\
\hline Age, months & & $18.3(12.0-36.0)$ \\
\hline Sex, Female & $497(47.7)$ & \\
\hline $\begin{array}{l}\text { Meat / meat alternatives consumption } \\
\text { (times per week) }\end{array}$ & & $14(0-21)^{*}$ \\
\hline not at all & $7(0.7)$ & \\
\hline few times per week & $78(7.5)$ & \\
\hline once per day & $199(19.1)$ & \\
\hline 2 times per day & $522(50.1)$ & \\
\hline$>2$ times per day & $237(22.7)$ & \\
\hline Red meat consumption in past 3 days, yes & $689(66.1)$ & \\
\hline $\mathrm{zBMI}^{\mathrm{a}}$ & & $0.10(-3.19-3.86)$ \\
\hline Underweight $(\mathrm{z}<-1)$ & $151(14.5)$ & \\
\hline Normal weight $(-1 \geq \mathrm{z} \leq-1)$ & $672(64.4)$ & \\
\hline Overweight $(1>\mathrm{z} \leq 2)$ & $133(12.8)$ & \\
\hline Obese $(z>2)$ & $50(4.8)$ & \\
\hline Missing & $37(3.6)$ & \\
\hline Birth weight, $\mathrm{kg}$ & & $3.3(0.7-5.2)$ \\
\hline$<2.5$ & $103(9.9)$ & \\
\hline $2.5-4.0$ & $767(73.5)$ & \\
\hline$>4.0$ & $87(8.3)$ & \\
\hline Missing & $86(8.3)$ & \\
\hline Maternal Ethnicity & & \\
\hline Caucasian & $684(65.6)$ & \\
\hline Asian & $192(18.4)$ & \\
\hline Other $^{\mathrm{a}}$ & $81(7.8)$ & \\
\hline Missing & $86(8.3)$ & \\
\hline $\begin{array}{l}\text { Median after-tax neighbourhood household } \\
\text { income, Can } \$^{\mathrm{a}}\end{array}$ & & \\
\hline 0-29,999 & $55(5.3)$ & \\
\hline $30,000-79,999$ & $765(73.4)$ & \\
\hline$\geq 80,000$ & $125(12.0)$ & \\
\hline Missing & $98(9.4)$ & \\
\hline Total breastfeeding duration, months & & $12.0(0-30.0)$ \\
\hline $0-6$ months & $157(15.1)$ & \\
\hline $6-12$ months & $431(41.3)$ & \\
\hline $12-24$ months & $369(35.4)$ & \\
\hline$\geq 24$ months & $20(1.9)$ & \\
\hline Missing & $66(6.3)$ & \\
\hline Daily cow's milk intake, cups & & $2.0(0-5.0)$ \\
\hline Cow's milk intake $>2$ cups/day, yes & $309(29.6)$ & \\
\hline Missing & $27(2.6)$ & \\
\hline Current bottle use, yes & $496(47.6)$ & \\
\hline Missing & $59(5.7)$ & \\
\hline
\end{tabular}


Grain product intake

less than 2 times a day

79 (7.6)

2 to 3 times a day

$582(55.8)$

4 to 5 times a day

$320(30.7)$

more than 5 times a day

$62(5.9)$

Fruit / vegetable intake in past 3 days, yes

5863 (56.2)

Serum ferritin $(\mu \mathrm{g} / \mathrm{L})$

Iron deficiency, yes

(serum ferritin $<14 \mu \mathrm{g} / \mathrm{L}$ )

Hemoglobin $(\mathrm{g} / \mathrm{L})$

$177(17.0)$

Missing

$120(78-151)$

Iron deficiency anemia, yes

(serum ferritin $<14 \mu \mathrm{g} / \mathrm{L}$ and

hemoglobin $\leq 110 \mathrm{~g} / \mathrm{L}$ )

Missing

$43(4.1)$

$43(4.1)$

${ }^{\mathrm{a}} \mathrm{BMI}=$ body mass index; Other includes: African, Caribbean, Latin American, North American Aboriginal; Can $\$=$ Canadian dollar *759 parents $(72.8 \%)$ reported that their child usually eats meat, fish, poultry or alternatives $\geq 2$ times per day, which is according to recommendations 
Table 2. Adjusted linear regression model for the association between meat consumption and median serum ferritin $(\mu \mathrm{g} / \mathrm{L})$

\begin{tabular}{|c|c|c|c|c|c|c|}
\hline \multirow{2}{*}{$\begin{array}{c}\text { Predictor } \\
\text { Meat / meat alternatives consumption }\end{array}$} & \multicolumn{2}{|c|}{$\beta(\log )(95 \% \mathrm{CI})$} & \multirow{2}{*}{$\begin{array}{c}\begin{array}{c}\text { Percent Change in } \\
\text { Serum Ferritin }\end{array} \\
0.51 \%\end{array}$} & \multicolumn{2}{|c|}{$\begin{array}{l}\text { Change in Median Serum } \\
\text { Ferritin } \mu \mathrm{g} / \mathrm{L}(95 \% \mathrm{CI})^{\mathrm{b}}\end{array}$} & \multirow{2}{*}{$\begin{array}{c}\boldsymbol{P} \text { Value } \\
0.16\end{array}$} \\
\hline & 0.005 & $(-0.002,0.012)$ & & 0.13 & $(-0.05,0.31)$ & \\
\hline Age, months & -0.0009 & $(-0.008,0.006)$ & $-0.09 \%$ & -0.02 & $(-0.20,0.15)$ & 0.79 \\
\hline Sex, Female & 0.084 & $(0.008,0.160)$ & $8.78 \%$ & 2.20 & $(0.20,4.35)$ & $0.03^{\mathrm{a}}$ \\
\hline zBMI, unit & -0.066 & $(-0.103,-0.029)$ & $-6.40 \%$ & -1.60 & $(-2.45,-0.72)$ & $0.0004^{\mathrm{a}}$ \\
\hline Birth weight, kg & 0.012 & $(-0.053,0.077)$ & $1.20 \%$ & 0.30 & $(-1.29,2.00)$ & 0.72 \\
\hline \multicolumn{7}{|l|}{ Maternal ethnicity } \\
\hline Caucasian & -- & -- & -- & -- & -- & -- \\
\hline Asian & 0.019 & $(-0.086,0.124)$ & $1.94 \%$ & 0.49 & $(-2.05,3.31)$ & 0.72 \\
\hline Other & -0.005 & $(-0.156,0.146)$ & $-0.49 \%$ & -0.12 & $(-3.61,3.93)$ & 0.95 \\
\hline \multicolumn{7}{|l|}{ Median neighbourhood household income } \\
\hline$\$ 0-29,999$ & 0.046 & $(-0.151,0.244)$ & $4.72 \%$ & 1.18 & $(-3.51,6.90)$ & 0.65 \\
\hline$\$ 30,000-79,999$ & 0.044 & $(-0.072,0.160)$ & $4.52 \%$ & 1.13 & $(-1.73,4.34)$ & 0.45 \\
\hline$\geq \$ 80,000$ & -- & - & -- & -- & -- & -- \\
\hline Breastfeeding duration, months & -0.017 & $(-0.024,-0.010)$ & $-1.68 \%$ & -0.42 & $(-0.60,-0.24)$ & $<0.0001^{\mathrm{a}}$ \\
\hline Daily cow's milk intake $>2$ cups/day, yes & -0.153 & $(-0.239,-0.068)$ & $-14.22 \%$ & -3.55 & $(-5.32,-1.64)$ & $0.0005^{\mathrm{a}}$ \\
\hline Current bottle use, yes & 0.096 & $(0.010,0.183)$ & $10.13 \%$ & 2.53 & $(0.24,5.03)$ & $0.03^{\mathrm{a}}$ \\
\hline \multicolumn{7}{|l|}{ Grain product intake } \\
\hline less than 2 times a day & 0.135 & $(-0.079,0.350)$ & $14.51 \%$ & 3.63 & $(-1.89,10.46)$ & 0.21 \\
\hline 2 to 3 times a day & 0.005 & $(-0.161,0.172)$ & $0.53 \%$ & 0.13 & $(-3.72,4.69)$ & 0.95 \\
\hline 4 to 5 times a day & 0.052 & $(-0.119,0.223)$ & $5.39 \%$ & 1.35 & $(-2.80,6.26)$ & 0.55 \\
\hline more than 5 times a day & -- & -- & -- & & -- & -- \\
\hline Fruit / vegetable intake in past 3 days, yes & 0.094 & $(0.013,0.176)$ & $9.91 \%$ & 2.48 & $(0.33,4.81)$ & $0.02^{\mathrm{a}}$ \\
\hline
\end{tabular}

Note: Adjusted beta estimates are reported to 3 decimal places for statistical precision. Negative values indicate a decrease in median

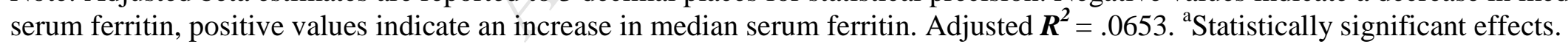


Table 3. Adjusted logistic regression model for association between meat consumption and iron deficiency (serum ferritin $<14 \mu \mathrm{g} / \mathrm{L}$ )

\begin{tabular}{|c|c|c|c|c|}
\hline Predictor & \multicolumn{2}{|c|}{$\beta(95 \%$ CI $)$} & OR $(95 \%$ CI $)$ & $\boldsymbol{P}$ \\
\hline Meat/meat alternatives consumption & -0.034 & $(-0.065,-0.003)$ & $0.97(0.94,0.99)$ & $0.03^{\mathrm{a}}$ \\
\hline Age, months & -0.027 & $(-0.059,0.005)$ & $0.97(0.94,1.01)$ & 0.10 \\
\hline Sex, Female & -0.110 & $(-0.449,0.229)$ & $0.90(0.64,1.26)$ & 0.52 \\
\hline zBMI, unit & 0.302 & $(0.138,0.466)$ & $1.35(1.15,1.59)$ & $0.0003^{\mathrm{a}}$ \\
\hline Birth weight, kg & -0.229 & $(-0.512,0.055)$ & $0.80(0.60,1.06)$ & 0.11 \\
\hline \multicolumn{5}{|l|}{ Maternal ethnicity } \\
\hline Caucasian & -- & -- & 1.00 & -- \\
\hline Asian & -0.052 & $(-0.521,0.416)$ & $0.95(0.59,1.52)$ & 0.83 \\
\hline Other & 0.018 & $(-0.636,0.672)$ & $1.02(0.53,1.96)$ & 0.96 \\
\hline \multicolumn{5}{|l|}{ Median neighbourhood household income } \\
\hline$\$ 0-29,999$ & -0.006 & $(-0.837,0.825)$ & $0.99(0.43,2.28)$ & 0.99 \\
\hline$\$ 30,000-79,999$ & -0.281 & $(-0.777,0.215)$ & $0.76(0.46,1.24)$ & 0.27 \\
\hline$\geq \$ 80,000$ & -- & -- & 1.00 & -- \\
\hline Breastfeeding duration, months & 0.058 & $(0.026,0.090)$ & $1.06(1.03,1.09)$ & $0.0004^{\mathrm{a}}$ \\
\hline Daily cow's milk intake $>2$ cups/day, yes & 0.599 & $(0.231,0.967)$ & $1.82(1.26,2.63)$ & $0.001^{\mathrm{a}}$ \\
\hline Current bottle use, yes & -0.344 & $(-0.726,0.038)$ & $0.71(0.48,1.04)$ & 0.08 \\
\hline \multicolumn{5}{|l|}{ Grain product intake } \\
\hline less than 2 times a day & -0.946 & $(-1.984,0.093)$ & $0.39(0.14,1.10)$ & 0.07 \\
\hline 2 to 3 times a day & -0.115 & $(-0.837,0.607)$ & $0.89(0.43,1.84)$ & 0.76 \\
\hline 4 to 5 times a day & -0.431 & $(-1.185,0.322)$ & $0.65(0.31,1.38)$ & 0.26 \\
\hline more than 5 times a day & -- & -- & 1.00 & -- \\
\hline Fruit and/or vegetable intake in past 3 days, yes & -0.222 & $(-0.582,0.138)$ & $0.80(0.56,1.15)$ & 0.23 \\
\hline Test & & $\chi^{2}$ & $d f$ & $\boldsymbol{P}$ \\
\hline Overall model evaluation - Likelihood ratio test & & 53.62 & 16 & $<0.0001$ \\
\hline Goodness-of-fit test - Hosmer \& Lemeshow & & 8.56 & 8 & 0.38 \\
\hline
\end{tabular}

Note: Adjusted beta estimates are reported to 3 decimal places for statistical precision. Negative values indicate a decrease in iron deficiency, positive values indicate an increase in iron deficiency. Adjusted $\boldsymbol{R}^{2}=.0838$. ${ }^{\text {a}}$ Statistically significant effects. 
Table 4. Adjusted linear regression model for the association between red meat consumption and median serum ferritin ( $\mu \mathrm{g} / \mathrm{L}$ ) among children who eat meat or meat alternatives according to recommendations

\begin{tabular}{|c|c|c|c|c|c|c|}
\hline \multirow{2}{*}{$\begin{array}{c}\text { Predictor } \\
\text { Red meat consumption in past } 3 \text { days, yes }\end{array}$} & \multicolumn{2}{|c|}{$\beta(\log )(95 \% \mathrm{CI})$} & \multirow{2}{*}{$\begin{array}{c}\begin{array}{c}\text { Percent Change in } \\
\text { Serum Ferritin }\end{array} \\
-1.78 \%\end{array}$} & \multicolumn{2}{|c|}{ 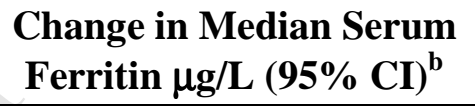 } & \multirow{2}{*}{$\begin{array}{c}\boldsymbol{P} \text { Value } \\
0.71\end{array}$} \\
\hline & -0.018 & $(-0.114,0.078)$ & & -0.45 & $(-2.70,2.03)$ & \\
\hline Age, months & -0.003 & $(-0.011,0.006)$ & $-0.26 \%$ & -0.07 & $(-0.27,0.14)$ & 0.54 \\
\hline Sex, Female & 0.086 & $(-0.004,0.175)$ & $8.93 \%$ & 2.23 & $(-0.09,4.77)$ & 0.06 \\
\hline zBMI, unit & -0.056 & $(-0.100,-0.011)$ & $-5.42 \%$ & -1.35 & $(-2.38,-0.28)$ & $0.01^{\mathrm{a}}$ \\
\hline Birth weight, kg & 0.025 & $(-0.051,0.102)$ & $2.57 \%$ & 0.64 & $(-1.25,2.69)$ & 0.52 \\
\hline \multicolumn{7}{|l|}{ Maternal ethnicity } \\
\hline Caucasian & -- & -- & -- & -- & -- & -- \\
\hline Asian & 0.042 & $(-0.075,0.160)$ & $4.33 \%$ & 1.08 & $(-1.81,4.33)$ & 0.48 \\
\hline Other & -0.095 & $(-0.274,0.084)$ & $-9.05 \%$ & -2.26 & $(-5.99,2.20)$ & 0.30 \\
\hline \multicolumn{7}{|l|}{ Median neighbourhood household income } \\
\hline$\$ 0-29,999$ & 0.064 & $(-0.167,0.294)$ & $6.56 \%$ & 1.64 & $(-3.84,8.54)$ & 0.59 \\
\hline$\$ 30,000-79,999$ & 0.048 & $(-0.081,0.176)$ & $4.87 \%$ & 1.22 & $(-1.95,4.82)$ & 0.47 \\
\hline$\geq \$ 80,000$ & -- & -- & -- & -- & -- & -- \\
\hline Breastfeeding duration, months & -0.017 & $(-0.026,-0.008)$ & $-1.70 \%$ & -0.42 & $(-0.64,-0.21)$ & $0.0001^{\mathrm{a}}$ \\
\hline Daily cow's milk intake >2 cups/day, yes & -0.123 & $(-0.223,-0.022)$ & $-11.56 \%$ & -2.89 & $(-5.00,-0.56)$ & $0.02^{\mathrm{a}}$ \\
\hline Current bottle use, yes & 0.073 & $(-0.027,0.173)$ & $7.58 \%$ & 1.89 & $(-0.67,4.73)$ & 0.15 \\
\hline \multicolumn{7}{|l|}{ Grain product intake } \\
\hline less than 2 times a day & 0.060 & $(-0.210,0.330)$ & $6.16 \%$ & 1.54 & $(-4.74,9.77)$ & 0.66 \\
\hline 2 to 3 times a day & 0.026 & $(-0.171,0.223)$ & $2.65 \%$ & 0.66 & $(-3.93,6.25)$ & 0.79 \\
\hline 4 to 5 times a day & 0.065 & $(-0.135,0.264)$ & $6.66 \%$ & 1.67 & $(-3.17,7.57)$ & 0.53 \\
\hline more than 5 times a day & -- & -- & -- & & -- & -- \\
\hline Fruit / vegetable intake in past 3 days, yes & 0.109 & $(0.014,0.204)$ & $11.55 \%$ & 2.89 & $(0.36,5.67)$ & $0.02^{\mathrm{a}}$ \\
\hline
\end{tabular}

Note: Adjusted beta estimates are reported to 3 decimal places for statistical precision. Negative values indicate a decrease in median serum ferritin, positive values indicate an increase in median serum ferritin. Adjusted $\boldsymbol{R}^{2}=.0595$. ${ }^{\mathrm{a}}$ Statistically significant effects. 
Table 5. Adjusted logistic regression model for association between red meat consumption and iron deficiency

$(<14 \mu \mathrm{g} / \mathrm{L})$ among children who eat meat or meat alternatives according to recommendations

\begin{tabular}{|c|c|c|c|c|}
\hline Predictor & \multicolumn{2}{|c|}{$\beta(95 \% \mathrm{CI})$} & OR $(95 \% \mathrm{CI})$ & $\boldsymbol{P}$ \\
\hline Red meat consumption in past 3 days, yes & 0.228 & $(-0.235,0.691)$ & $1.26(0.79,1.99)$ & 0.33 \\
\hline Age, months & -0.031 & $(-0.071,0.009)$ & $0.97(0.93,1.01)$ & 0.13 \\
\hline Sex, Female & -0.078 & $(-0.491,0.334)$ & $0.92(0.61,1.40)$ & 0.71 \\
\hline zBMI, unit & 0.339 & $(0.131,0.546)$ & $1.40(1.14,1.73)$ & $0.001^{\mathrm{a}}$ \\
\hline Birth weight, kg & -0.397 & $(-0.740,-0.054)$ & $0.67(0.48,0.95)$ & $0.02^{\mathrm{a}}$ \\
\hline \multicolumn{5}{|l|}{ Maternal ethnicity } \\
\hline Caucasian & -- & -- & 1.00 & -- \\
\hline Asian & -0.252 & $(-0.812,0.308)$ & $0.78(0.44,1.36)$ & 0.38 \\
\hline Other & 0.305 & $(-0.422,1.031)$ & $1.36(0.66,2.80)$ & 0.41 \\
\hline \multicolumn{5}{|l|}{ Median neighbourhood household income } \\
\hline$\$ 0-29,999$ & -0.504 & $(-1.568,0.561)$ & $0.60(0.21,1.75)$ & 0.35 \\
\hline$\$ 30,000-79,999$ & -0.359 & $(-0.920,0.201)$ & $0.70(0.40,1.22)$ & 0.21 \\
\hline$\geq \$ 80,000$ & -- & -- & 1.00 & -- \\
\hline Breastfeeding duration, months & 0.070 & $(0.030,0.110)$ & $1.07(1.03,1.12)$ & $0.0007^{\mathrm{a}}$ \\
\hline Daily cow's milk intake $>2$ cups/day, yes & 0.401 & $(-0.048,0.850)$ & $1.49(0.95,2.34)$ & 0.08 \\
\hline Current bottle use, yes & -0.216 & $(-0.669,0.236)$ & $0.81(0.51,1.27)$ & 0.35 \\
\hline \multicolumn{5}{|l|}{ Grain product intake } \\
\hline less than 2 times a day & -1.219 & $(-2.720,0.282)$ & $0.30(0.07,1.33)$ & 0.11 \\
\hline 2 to 3 times a day & -0.154 & $(-1.049,0.741)$ & $0.86(0.35,2.10)$ & 0.74 \\
\hline 4 to 5 times a day & -0.468 & $(-1.385,0.448)$ & $0.63(0.25,1.57)$ & 0.32 \\
\hline more than 5 times a day & -- & -- & 1.00 & -- \\
\hline Fruit and/or vegetable intake in past 3 days, yes & -0.325 & $(-0.760,0.110)$ & $0.72(0.47,1.12)$ & 0.14 \\
\hline Test & \multicolumn{2}{|r|}{$\chi^{2}$} & $d f$ & $\boldsymbol{P}$ \\
\hline Overall model evaluation - Likelihood ratio test & \multicolumn{2}{|c|}{39.38} & 16 & 0.001 \\
\hline Goodness-of-fit test - Hosmer \& Lemeshow & \multicolumn{2}{|c|}{5.96} & 8 & 0.65 \\
\hline
\end{tabular}

Note: Adjusted beta estimates are reported to 3 decimal places for statistical precision. Negative values indicate a decrease in

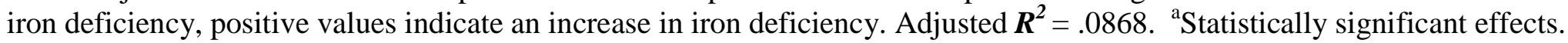


